\title{
Screening of Immunostimulatory Probiotic Lactic Acid Bacteria from Chicken Feces as Animal Probiotics
}

\author{
Eun-Kyung Lee, Na-Kyoung Lee, Si-Kyung Lee ${ }^{1}$, Hyo-Ihl Chang ${ }^{2}$, and Hyun-Dong Paik* \\ Division of Animal Life Science and Bio/Molecular Informatics Center, Konkuk University, Seoul 143-701, Korea \\ ${ }^{1}$ Department of Applied Biology and Chemistry, Konkuk University, Seoul 143-701, Korea \\ ${ }^{2}$ School of Life Science and Biotechnology, Korea University, Seoul 136-701, Korea
}

\begin{abstract}
The principal objective of this study was to screen and select acid-tolerant Lactobacillus strains from chicken feces, feeds, and other sources. Fourty six strains evidencing acid tolerance $(\mathrm{pH} \mathrm{3.5)} \mathrm{were} \mathrm{isolated} \mathrm{in} \mathrm{this} \mathrm{study.} \mathrm{Among} \mathrm{them,} \mathrm{nine} \mathrm{strains}$ exhibited marked immunostimulatory effects. Therefore, nine candidate strains were characterized for probiotic use. In order to evaluate macrophage activation, NO production was measured using RAW 264.7 cells. In particular, three strains (FC812, FC222, and FC113) evidenced the highest levels of NO production measured at $38.39 \pm 20.01,35.06 \pm 27.73$, and $33.88 \pm 15.99 \mu \mathrm{M}$, respectively, at a concentration of $10^{8} \mathrm{CFU} / \mathrm{mL}$. The majority of strains, with the exception of strain FC322, evidenced marked resistance to artificial gastric juice ( $\mathrm{pH} 2.5$ with $1 \%(\mathrm{w} / \mathrm{v})$ pepsin). Additionally, strains FC222, FC421, FC511, and FC721 were highly resistant to artificial bile acid ( $0.1 \%(w / v)$ oxgall), whereas strains FC113, FC322, FC422, FC621, and FC812 were the least resistant to bile. All nine strains exerted antimicrobial effects against chickenrelated pathogens. Additionally, all nine strains were found to be resistant to several antibiotics. The isolated strains, except for strain FC322, were tentatively identified as Lactobacillus salivarius, using an API 50 CHL kit. These results demonstrate that some probiotic organisms may potentially probiotic properties, and thus may serve as an effective alternative to antibiotics in animal applications.
\end{abstract}

Key words: animal probiotics, immunostimulatory effect, chicken feces, lactic acid bacteria

\section{Introduction}

Antibiotics have been used as feed additives to promote the productivity of livestock farming, in addition to their conventional use in therapy (Wierup, 2001). However, the extensive use of antibiotics to promote animal growth rates has resulted in an imbalance in beneficial intestinal flora, as well as the appearance of resistant bacteria. Additionally, the presence of residual antibiotics in meat and eggs is unacceptable. In order to safeguard human health, the Food and Agriculture Organization/World Health Organization (FAO/WHO) have established standards for maximum residue limits (Lee and Choi, 2006; Muriuki et al., 2001; Pascual et al., 1999). Therefore, there is an increasing interest in probiotics as an alternative to the use of antibiotics.

\footnotetext{
*Corresponding author: Hyun-Dong Paik, Division of Animal Life Science and Bio/Molecular Informatics Center, Konkuk University, Seoul 143-701, Korea. Tel.: 82-2-2049-6011, Fax: 82-2-455-1044, E-mail: hdpaik@konkuk.ac.kr
}

Probiotics have been defined by the FAO/WHO as "live microorganisms which, when administered in adequate amounts, confer a health benefit to the host" (Shanahan, 2004). The most common probiotic bacteria are the lactic acid bacteria, such as the lactobacilli and bifidobacteria, certain spore-forming Bacillus species, or yeasts like Saccharomyces boulardii (Hoa et al., 2000; Jun et al., 2000; Shin et al., 1999). Extensive studies have been conducted to determine the relevant characteristics of probiotics, including survival under gastric conditions, improvements in unbalanced intestinal microbiota, reductions of lactose intolerance, the prevention of antibioticinduced diarrhea, reduction of cholesterol levels, prevention of colon cancer, and stimulation of immune system (De Rodas et al., 1996; Kimura et al., 1997; Pool-Zobel et al., 1996; Reddy et al., 1998; Sanders, 2003).

The lactic acid bacteria (LAB) are closely associated with human and animal environments. The LABs are classified as GRAS (Generally Recognized as Safe) organisms, and can be detected in the gastro-intestinal tracts of humans and animals, and also in fermented food (Holza- 
pfel et al., 1993; Klein, 2003). Various strains of LAB isolated from the gut evidence probiotic properties, as do fermented dairy products and vegetables (Vizoso Pinto et al., 2006). They generate antimicrobial substances against undesirable pathogens including organic acid, hydrogen peroxide, ethanol, diacetyl, carbon dioxide, and bacteriocins (Ayad et al., 2002; Caplice and Fitzgerald, 1999).

Nitric oxide (NO) performs a central role in several physiological functions, and is also operant in the onset and maintenance of certain pathological conditions, including immune system issues (Marin and RodriguezMartinez, 1997). NO interacts with cytokines or microbial compounds (Bogdan, 2001) and is generated during the oxidation of L-arginine to L-citrulline by the enzyme NO synthase (NOS) (Liao et al., 1995). Three isoforms of NOS are currently known: neuronal NOS (nNOS), endothelial NOS (eNOS), and inducible NOS (iNOS) (Kanno et al., 2006). Among them, iNOS can generate high levels of NO in immune responses (Guzik et al., 2003), and the NO produced by iNOS is observed principally in cells of the macrophage-monocyte lineage such as monocytes and macrophages (Oleszak et al., 1997). In general, moderately high levels of NO may exert cytostatic or cytotoxic effects, including anti-bacterial, anti- viral, anti-protozoa, and anti-apoptotic effects on immune cells (Karpuzoglu and Ahmed, 2006; McCartney-Francis et al., 1993), whereas excessively high levels of NO are involved in inflammatory autoimmune diseases (Bogdan et al., 2000). Therefore, $\mathrm{NO}$ can be viewed as a highly bioactive, but potentially toxic molecule (Weisz et al., 1996).

In this study, we screened and selected Lactobacillus spp. from chicken feces for probiotic use, as an alternative to the use of antibiotics in animals. The selected strains were assessed with regard to their probiotic characteristics, including their resistances to artificial gastric juice and bile acid, antimicrobial activity, antibiotic susceptibility, and immunostimulatory effects.

\section{Materials and Methods}

\section{Isolation of LAB}

Samples of chicken feces were provided by Ahnil Farm in Yunchun, Korea. For the isolation of Lactobacillus spp. from chicken feces, $3 \mathrm{~g}$ of collected samples were suspended in $30 \mathrm{~mL}$ of $0.85 \%$ saline $(\mathrm{pH} 3.5)$ and incubated at room temperature for $2 \mathrm{~h}$. One hundred $\mu \mathrm{L}$ of diluted suspensions were spread onto LBS (Lactobacillus selection medium; BD BBL, Cockeysville, MD, USA) agar plates. After the plates were incubated at $37^{\circ} \mathrm{C}$ for $24 \mathrm{~h}$, colonies with different morphologies were selected. The isolates were grown in lactobacilli MRS broth (Difco Laboratories, Detroit, MI, USA) at $37^{\circ} \mathrm{C}$, and stored as stock solutions in $20 \%(\mathrm{v} / \mathrm{v})$ glycerol at $-70^{\circ} \mathrm{C}$.

\section{Identification of strains}

The selected LAB strains were identified by their biochemical carbohydrate fermentation patterns, using an API 50 CHL kit (BioMerieux, Lyon, France). The colonies were initially suspended in API 50 CHL medium and the 50 compartments of the strips were inoculated. Incubation was conducted at $37^{\circ} \mathrm{C}$ under aerobic conditions, and the reactions were observed at 24 and $48 \mathrm{~h}$. The biochemical profiles were obtained and entered into the identification program.

\section{Cell culture}

The murine macrophage cell line (RAW 264.7, KCLB 40071) was purchased from the Korean Cell Line Bank (KCLB; Seoul National University, Seoul, Korea). The cell lines were cultured in DMEM (Dulbecco's Modified Eagle Medium; Gibco Laboratories, Grand Island, NY, USA) containing $10 \%$ fetal bovine serum (Gibco Laboratories) and $1 \%$ streptomycin-penicillin (Gibco Laboratories) at $37^{\circ} \mathrm{C}$ in an atmosphere of $5 \% \mathrm{CO}_{2} / 95 \%$ air. For the NO assay, the cells were seeded in new dishes and grown to $80 \%$ confluence.

\section{Nitric oxide assay}

The RAW 264.7 cells were seeded at a density of $2 \times 10^{4}$ cells/well in 96-well culture plates and incubated at $37^{\circ} \mathrm{C}$ for $24 \mathrm{~h}$ in an atmosphere of $5 \% \mathrm{CO}_{2} / 95 \%$ air. RAW 264.7 cells were activated via the addition of heat-treated $\left(100^{\circ} \mathrm{C}, 30 \mathrm{~min}\right)$ suspension of the LAB stains selected in medium at concentrations of $1 \times 10^{6}, 1 \times 10^{7}$, and $1 \times 10^{8}$ $\mathrm{CFU} / \mathrm{mL}$, respectively. After $48 \mathrm{~h}$ of incubation, the conditioned media $(100 \mu \mathrm{L})$ were allowed to react with an equal volume of Griess reagent (Fluka, Steinheim, Germany) for $15 \mathrm{~min}$ at room temperature. The optical density was determined at $540 \mathrm{~nm}$ with an enzyme-linked immunosorbent assay (ELISA) plate reader (Molecular Devices, Sunnyvale, CA, USA). Nitric oxide production was evaluated via comparisons of the optical density with the standard curve obtained with sodium nitrite (Sigma, St. Louis, MO, USA).

\section{Tolerance to artificial gastric juice and artificial bile acid}

Tolerance to artificial gastric juice and artificial bile 
acid was measured in accordance with the method developed by Kobayashi et al. (1974). The selected LAB strains were suspended in MRS broth containing $1 \%(\mathrm{w} / \mathrm{v})$ pepsin (Sigma), adjusted to $\mathrm{pH} 2.5$ with $0.1 \mathrm{M} \mathrm{HCl}$, and incubated at $37^{\circ} \mathrm{C}$ for $2 \mathrm{~h}$. Artificial bile acid tolerance was determined by cultivating cells treated with artificial gastric juice. The cells were incubated at $37^{\circ} \mathrm{C}$ for $24 \mathrm{~h}$ in artificial bile acid consisting of MRS broth containing $0.1 \%(\mathrm{w} / \mathrm{v})$ oxgall (Difco Laboratories). The numbers of viable cells were determined by incubating aliquots for $24 \mathrm{~h}$ on MRS agar plates at $37^{\circ} \mathrm{C}$.

\section{Antimicrobial activities}

The antimicrobial activities of selected LAB strains were assessed via a modified version of the deferred method against indicator organisms. Eight types of microorganisms (Avian pathogenic $E$. coli cell $\mathrm{B} / 06 / 31$, Avian pathogenic E. coli cell B/06/63, Avian pathogenic E. coli cell B/06/80, E. coli (-) control, Staphylococcus aureus SEA. CE. T-C, Salmonella pullorum ATCC 10398, Salmonella gallinarum ATCC 9184, and Salmonella Enteritidis ATCC 13076) were employed as the indicator strains. The pathogenic strains, isolated from chickens and hatcheries, were obtained from Dr. Hyung-Kwan Jang (Chonbuk National University, Korea). Overnight cultures in MRS broth were inoculated as $3 \mu \mathrm{L}$ spots on MRS agar plates, and then incubated at $37^{\circ} \mathrm{C}$ for $24 \mathrm{~h}$ to allow for colony development. Five $\mathrm{mL}$ of soft TSA $(0.75 \%$ agar $)$, containing approximately $10^{7}$ cells of indicator strains per overlay, were overlaid on MRS plates, and after $24 \mathrm{~h}$ of incubation at $37^{\circ} \mathrm{C}$, an inhibition zone became clearly visible. The strength of the antimicrobial activities was expressed in terms of the diameter $(\mathrm{mm})$ of the inhibition zone, and the results presented are the means of duplicate tests.

\section{Antibiotic susceptibility}

The antibiotics employed for the antibiotic susceptibility assay were nisin, streptomycin, neomycin, roxithromycin, chloramphenicol, gentamycin, rifampicin, erythromycin, ciprofloxacin, and ampicillin. Antibiotic susceptibility was determined via the paper disk method. Soft agar $(0.75 \%, \mathrm{w} / \mathrm{v})$, containing $10^{7}$ cells of the selected LAB strains, was overlaid on agar plates. After solidification, sterile paper disks were aseptically laid onto the surface of the agar, and then antibiotic diluents were immediately applied to each disk. The agar plates with the antibiotic disks were then incubated at $37^{\circ} \mathrm{C}$ for $24 \mathrm{~h}$. The inhibition zone was measured from the edge of the disk.

\section{Results and Discussion}

\section{Screening of LAB from chicken feces}

The use of LABs as probiotics in farm animals is increasing many researches including isolation, characterization and so on. The principal objective of this study was to screen and select LAB from chicken feces, feeds, and other sources, using acid tolerance characteristics. Forty six LAB isolates from chicken feces were screened for their acid tolerance ( $\mathrm{pH} 3.5$ for $2 \mathrm{~h}$ ). Forty six colonies representing a variety of different colony morphologies were observed and randomly selected for further analysis. Selection was based on the collection of samples from different sites. The immunostimulatory effects of probiotics is an increasingly important characteristic reference. These isolates were then screened for immunostimulatory activity via nitric oxide production by in vitro culture experiments using RAW 264.7 murine macrophages. Among them, nine strains (FC113, FC222, FC322, FC421, FC422, FC511, FC621, FC721, and FC812) showed high NO production (Table 1). Strains FC812, FC222, and FC113 were shown to produce NO levels of $38.39 \pm 20.01,35.06 \pm 27.73$, and $33.88 \pm 15.99 \mu \mathrm{M}$, respectively, at concentrations of $10^{8} \mathrm{CFU} / \mathrm{mL}$. Thus, $9 \mathrm{LAB}$ strains were selected for further analyses of probiotic characteristics.

\section{Identification of LAB strains}

Nine LAB strains were analyzed and tentatively identified via their physiological characteristics, which were determined using an API 50 CHL kit (data not shown). We tentatively identified strains FC113, FC222, FC421, FC422, FC511, FC621, FC721, and FC812 as Lactobacillus salivarius. Thus, these eight strains were tentatively named, respectively, L. salivarius FC113, FC222, FC421,

Table 1. NO productions of microbial strains isolated from chicken feces $(\mu \mathrm{M})$

\begin{tabular}{cccc}
\hline \hline \multirow{2}{*}{ Strain } & \multicolumn{3}{c}{ Concentration of cells } \\
\cline { 2 - 4 } & $10^{6}$ & $10^{7}$ & $10^{8}$ \\
\hline FC113 & $0.35 \pm 1.56$ & $12.51 \pm 0.90$ & $33.88 \pm 15.99$ \\
FC222 & $3.10 \pm 1.48$ & $14.86 \pm 2.93$ & $35.06 \pm 27.73$ \\
FC322 & $1.53 \pm 1.66$ & $13.10 \pm 3.34$ & $23.49 \pm 6.01$ \\
FC421 & $0.75 \pm 0.68$ & $10.94 \pm 1.76$ & $21.92 \pm 6.48$ \\
FC422 & $4.27 \pm 2.38$ & $15.45 \pm 1.36$ & $16.24 \pm 3.06$ \\
FC511 & $6.43 \pm 4.93$ & $12.90 \pm 0.68$ & $13.10 \pm 3.24$ \\
FC621 & $8.39 \pm 4.79$ & $21.14 \pm 7.02$ & $23.29 \pm 9.72$ \\
FC721 & $7.02 \pm 4.00$ & $13.29 \pm 2.70$ & $18.78 \pm 3.24$ \\
FC812 & $6.63 \pm 0.90$ & $20.16 \pm 4.90$ & $38.39 \pm 20.01$ \\
\hline
\end{tabular}

Values are Mean \pm SE. 
FC422, FC511, FC621, FC721, and FC812. FC322 could not be identified because no significant results were generated with an API 50 CHL kit.

\section{Tolerance to artificial gastric juice and artificial bile acid}

Probiotic bacteria must survive under gastric conditions in the stomach (low $\mathrm{pH}$ ) in order to execute their various physiological functions. The viabilities of nine Lactobacillus strains were determined in artificial gastric juice ( $\mathrm{pH}$ 2.5) for $2 \mathrm{~h}$ (Table 2). L. salivarius FC113, FC222, FC421, FC422, FC511, FC621, FC721, and FC812 evidenced high rates of survival (41-112\%), whereas strain FC322 was the most sensitive under gastric conditions (1.4\%). In particular, L. salivarius FC113 and FC522 evidenced survival rates of almost $100 \%$. The results of similar studies showed that $L$. acidophilus, $L$. rhamnosus, $L$. reuteri, L. casei, L. bulgaricus, Lactococcus lactis, and Streptococcus thermophilus are capable of growing well at low pH (Vinderola and Reinheimer, 2003; Xanthopoulos, 2000). L. salivarius was reported to survive for 30 min at $\mathrm{pH} 2$ and for $6 \mathrm{~h}$ at $\mathrm{pH} 3$ (Lim et al., 2007), and to be a survival rate of approximately $50 \%$ after $2 \mathrm{~h}$ of incubation in artificial gastric juice (pH 3) (Park et al., 1999).

Probiotics also need to be resistant to bile acids, as they pass through the duodenum in order to reach the small intestinal tract (Ha et al., 2004; Mainville et al., 2005). Table 2 shows the viability of nine Lactobacillus strains treated with artificial gastric juice in artificial bile acid for an incubation period of 24 h. L. salivarius FC222, FC511, and FC721 evidenced significantly higher survival rates (more than 70\%) in artificial bile acid. However, L. salivarius FC113, FC621, and FC812, and strain FC322 were the least bile-resistant. The broad variation in bile sensitivity is consistent with the findings of many studies (Chateau et al., 1994; Ibrahim and Bezkorovainy, 1993).
Therefore, a consensus is emerging that broad variations exist in the susceptibility of probiotic bacteria to bile, and also that this property is specific as strain.

\section{Antimicrobial activities against chicken-related pathogens}

The modified deferred method was employed for the detection of the antimicrobial activities of the nine selected Lactobacillus strains against pathogenic microorganisms isolated from chickens and environmental specimens from hatcheries. All 9 strains of Lactobacillus evidenced antimicrobial activities, although the antimicrobial patterns they exhibited against the tested pathogenic microorganisms varied considerably (Table 3 ). In particular, L. salivarius FC422 and FC621 evidenced a broad range of antimicrobial activities against all tested pathogenic microorganisms. L. salivarius FC422 and FC621 produced a maximum zone of inhibition against $S$. Enteritidis 13676 and S. gallinarum 9184, respectively. L. salivarius FC113 and FC812 failed to evidence any detectable antimicrobial effects against APEC B/06/63 and $S$. gallinarum 9184, respectively. The growth of $S$. Enteritidis 13676 was inhibited effectively by all Lactobacillus strains. However, the least antimicrobial effects were noted against $S$. aureus SEA. CE. T-C. The antimicrobial activities of many LAB strains are principally attributable to lactic acid production, and the acid suppresses the contamination or growth of acid-sensitive intestinal pathogenic bacteria, including Staphylococcus, Salmonella, and coliform (Kim, 2005).

\section{Antibiotic susceptibility}

Probiotics must evidence some antibiotic tolerance, as many antimicrobial chemicals are employed as feed additives (Zhou et al., 2005). LABs, in general, must be somewhat resistant to antibiotics, in order to survive in

Table 2. Viability of microbial strains isolated from chicken feces in artificial gastric juice for $\mathbf{2} \mathbf{h}$, and in artificial bile acid after artificial gastric juice treatment (for $2 \mathrm{~h}$ ) for $24 \mathrm{~h}$

\begin{tabular}{|c|c|c|c|c|c|c|}
\hline \multirow{2}{*}{ Strain } & \multicolumn{3}{|c|}{ Artificial gastric juice $(\mathrm{CFU} / \mathrm{mL})$} & \multicolumn{3}{|c|}{ Artificial bile acid (CFU/mL) } \\
\hline & Control & $1 \%$ Pepsin (pH 2.5) & Viability (\%) & Control & $0.1 \%$ Oxgall & Viability (\%) \\
\hline FC113 & $1.4 \times 10^{8}$ & $1.3 \times 10^{8}$ & 96.4 & $7.3 \times 10^{9}$ & $1.7 \times 10^{7}$ & 0.2 \\
\hline FC222 & $4.0 \times 10^{8}$ & $3.2 \times 10^{8}$ & 80.8 & $1.8 \times 10^{10}$ & $1.4 \times 10^{10}$ & 76.6 \\
\hline FC322 & $1.1 \times 10^{8}$ & $1.5 \times 10^{6}$ & 1.4 & $3.4 \times 10^{7}$ & $5.2 \times 10^{4}$ & 0.2 \\
\hline FC421 & $3.4 \times 10^{8}$ & $3.0 \times 10^{8}$ & 89.4 & $1.5 \times 10^{10}$ & $5.0 \times 10^{9}$ & 33.7 \\
\hline FC422 & $5.4 \times 10^{8}$ & $2.2 \times 10^{8}$ & 41.3 & $1.9 \times 10^{10}$ & $8.1 \times 10^{8}$ & 4.4 \\
\hline FC522 & $2.0 \times 10^{8}$ & $2.2 \times 10^{8}$ & 111.6 & $1.8 \times 10^{10}$ & $1.5 \times 10^{10}$ & 79.2 \\
\hline FC621 & $4.2 \times 10^{8}$ & $3.1 \times 10^{8}$ & 75.0 & $2.3 \times 10^{10}$ & $1.9 \times 10^{8}$ & 0.8 \\
\hline FC721 & $5.0 \times 10^{8}$ & $2.4 \times 10^{8}$ & 47.1 & $2.7 \times 10^{10}$ & $2.1 \times 10^{10}$ & 78.7 \\
\hline FC812 & $6.3 \times 10^{8}$ & $2.7 \times 10^{8}$ & 43.0 & $2.8 \times 10^{10}$ & $3.0 \times 10^{8}$ & 1.1 \\
\hline
\end{tabular}


the intestine and allow for successful preventive antibiotic treatment. Antibiotics are important in the health care industry, in which they are used to fight bacterial infections. However, bacteria are capable of developing antibiotic resistance (Danielsen and Wind, 2003). All Lactobacillus strains were shown to be broadly resistant to streptomy- cin, and also resistant to nisin at concentrations below 200 $\mu \mathrm{g} / \mathrm{mL}$ (Table 4). They also proved resistant to neomycin (except for strain FC322 and L. salivarius FC621), and gentamycin (except for L. salivarius FC222 and strain FC322). By way of contrast, they proved highly susceptible to rifampicin, chloramphenicol and ampicillin at 10

Table 3 Antimicrobial effect of microbial strains isolated from chicken feces against avian pathogens by deferred method

\begin{tabular}{|c|c|c|c|c|c|c|c|c|c|}
\hline \multirow{2}{*}{ Strain } & \multicolumn{9}{|c|}{ Diameter of inhibitory clear zone (mm) } \\
\hline & FC113 & FC222 & FC322 & FC421 & FC422 & FC511 & FC621 & FC721 & FC812 \\
\hline $\mathrm{APEC}^{1)} \mathrm{B} / 06 / 31$ & 9 & 3 & 2 & 10 & 10 & 8 & 9 & 8 & 8 \\
\hline APEC B/06/63 & 0 & 3 & 3 & 10 & 10 & 14 & 10 & 8 & 11 \\
\hline APEC B/06/80 & 4 & 5 & 10 & 10 & 14 & 9 & 14 & 14 & 20 \\
\hline S. aureus SEA. CE. T-C & 5 & 3 & 2 & 6 & 7 & 4 & 5 & 4 & 9 \\
\hline S. pullorum 10398-2 & 4 & 9 & 2 & 4 & 5 & 4 & 7 & 5 & 6 \\
\hline S. gallinarum 9184 & 10 & 9 & 3 & 8 & 8 & 8 & 50 & 12 & 0 \\
\hline$S$. Enteritidis 13676 & 10 & 30 & 6 & 10 & 70 & 18 & 20 & 14 & 16 \\
\hline E. coli (-) control & 13 & 10 & 4 & 14 & 14 & 10 & 12 & 11 & 10 \\
\hline
\end{tabular}

Avian pathogenic E. coli cell.

Table 4. Resistance of microbial strains isolated from chicken feces to various antibiotics

\begin{tabular}{|c|c|c|c|c|c|c|c|c|c|c|}
\hline \multicolumn{2}{|c|}{ Antibiotics $(\mu \mathrm{g} / \mathrm{mL})$} & FC113 & FC222 & FC322 & FC421 & FC422 & FC511 & FC621 & FC721 & FC812 \\
\hline \multirow{4}{*}{ Nisin } & 10 & $++^{1)}$ & + & + & + & + & + & + & + & + \\
\hline & 50 & + & + & + & + & + & + & + & + & + \\
\hline & 100 & + & + & + & + & + & + & + & + & + \\
\hline & 200 & + & -2) & + & - & + & + & - & - & + \\
\hline \multirow{4}{*}{$\begin{array}{l}\text { Streptomy- } \\
\quad \text { cin }\end{array}$} & 10 & + & + & + & + & + & + & + & + & + \\
\hline & 50 & + & + & + & + & + & + & + & + & + \\
\hline & 100 & + & + & + & + & + & + & + & + & + \\
\hline & 200 & + & + & + & + & + & + & + & + & + \\
\hline \multirow{4}{*}{ Neomycin } & 10 & + & + & + & + & + & + & + & + & + \\
\hline & 50 & + & + & + & + & + & + & + & + & + \\
\hline & 100 & + & + & - & + & + & + & - & + & + \\
\hline & 200 & + & + & - & + & + & + & - & + & + \\
\hline \multirow{4}{*}{$\begin{array}{l}\text { Roxithro- } \\
\text { mycin }\end{array}$} & 10 & + & + & + & + & + & + & + & + & + \\
\hline & 50 & + & + & + & - & - & - & - & - & + \\
\hline & 100 & - & + & + & - & - & - & - & - & + \\
\hline & 200 & - & + & + & - & - & - & - & - & + \\
\hline \multirow{4}{*}{$\begin{array}{l}\text { Chloram- } \\
\text { phenicol }\end{array}$} & 10 & - & + & + & + & + & + & + & + & + \\
\hline & 50 & - & - & - & - & - & - & - & - & - \\
\hline & 100 & - & - & - & - & - & - & - & - & - \\
\hline & 200 & - & - & - & - & - & - & - & - & - \\
\hline \multirow{4}{*}{ Gentamycin } & 10 & + & + & + & + & + & + & + & + & + \\
\hline & 50 & + & + & - & + & + & + & + & + & + \\
\hline & 100 & + & - & - & + & + & + & + & + & + \\
\hline & 200 & + & - & - & + & + & + & + & + & + \\
\hline \multirow{4}{*}{ Rifampicin } & 10 & - & - & - & - & - & - & - & - & - \\
\hline & 50 & - & - & - & - & - & - & - & - & - \\
\hline & 100 & - & - & - & - & - & - & - & - & - \\
\hline & 200 & - & - & - & - & - & - & - & - & - \\
\hline
\end{tabular}

1)+, growth.

2)-, no growth. 
Table 4. Conitnued

\begin{tabular}{|c|c|c|c|c|c|c|c|c|c|c|}
\hline \multicolumn{2}{|c|}{ Antibiotics $(\mu \mathrm{g} / \mathrm{mL})$} & FC113 & FC222 & FC322 & FC421 & FC422 & FC511 & FC621 & FC721 & FC812 \\
\hline \multirow{4}{*}{$\begin{array}{l}\text { Erythromy- } \\
\quad \text { cin }\end{array}$} & 10 & + & + & + & + & + & - & + & + & + \\
\hline & 50 & - & + & + & - & + & - & - & - & + \\
\hline & 100 & - & + & - & - & + & - & - & - & + \\
\hline & 200 & - & + & - & - & - & - & - & - & + \\
\hline \multirow{4}{*}{$\begin{array}{l}\text { Ciprofloxa- } \\
\quad \text { cin }\end{array}$} & 10 & + & + & - & + & + & + & + & + & + \\
\hline & 50 & + & + & - & + & + & + & + & + & + \\
\hline & 100 & + & + & - & + & - & + & + & - & + \\
\hline & 200 & - & + & - & + & - & + & + & - & + \\
\hline \multirow{4}{*}{ Ampicillin } & 10 & + & - & - & + & + & + & - & + & + \\
\hline & 50 & - & - & - & - & - & + & - & - & - \\
\hline & 100 & - & - & - & - & - & - & - & - & - \\
\hline & 200 & - & - & - & - & - & - & - & - & - \\
\hline
\end{tabular}

$\mu \mathrm{g} / \mathrm{mL}$ (L. salivarius FC511 at concentrations over $50 \mu \mathrm{g}$ / $\mathrm{mL}$ ). Roxithromycin inhibited L. salivarius FC113 at concentrations of over $50 \mu \mathrm{g} / \mathrm{mL}$, and L. salivarius FC421, FC422, FC511, FC621, and FC721 at over $10 \mu \mathrm{g} / \mathrm{mL}$ concentration, whereas L. salivarius FC222, FC322, and FC812 did exhibit resistance. L. salivarius FC222 and FC812 proved resistant to erythromycin; moreover, $L$. salivarius FC422 was also resistant to erythromycin at concentrations below $200 \mu \mathrm{g} / \mathrm{mL}$. However, erythromycin inhibited L. salivarius FC511 and L. salivarius FC113, FC421, FC621, and FC721 at concentrations of over 10 $\mu \mathrm{g} / \mathrm{mL}$, as well as L. salivarius FC322 at concentrations above $50 \mu \mathrm{g} / \mathrm{mL}$. All Lactobacillus strains, with the exception of strain FC322, evidenced ciprofloxacin resistance (L. salivarius FC113 at concentrations below 200 $\mu \mathrm{g} / \mathrm{mL}$, and L. salivarius FC422 and FC721 at concentrations below $100 \mu \mathrm{g} / \mathrm{mL}$ ).

All in all, our results led us to the conclusion that $L$. salivarius strains have probiotic properties, including NO production, marked resistance to artificial gastric juice and bile acid, antimicrobial activities, and antibiotic tolerance. These findings demonstrate that these probiotic organisms evidence potential probiotic properties as an alternative to antibiotic use in animals. However, strain FC322 evidences poor probiotic characteristics, particularly low survival rates under gastric conditions.

\section{Acknowledgments}

This study was supported by a research grant from the BioGreen 21 Program and Priority Research Centers Program through the National Research Foundation of Korea (NRF) funded by the Ministry of Education, Science and Technology (2009-0093824), Korea.

\section{References}

1. Ayad, E. H. E., Verheul, A., Wouters, J. T. M., and Smit, G. (2002) Antimicrobial-producing wild lactococci isolated from artisanal and non-dairy origins. Int. Dairy J. 12, 145150 .

2. Bogdan, C., Rollinghoff, M., and Diefenbach, A. (2000) The role of nitric oxide in innate immunity. Immunol. Rev. 173, 17-26.

3. Bogdan, C. (2001) Nitric oxide and the immune response. Nat. Immunol. 2, 907-916.

4. Caplice, E. and Fitzgerald, G. F. (1999) Food fermentation: role of microorganisms in food production and preservation. Int. J. Food Microbiol. 50, 131-149.

5. Chateau, N., Deschamps, A. M., and Sassi, A. H. (1994) Heterogeneity of bile salts resistance in the Lactobacillus isolates of a probiotic consortium. Lett. Appl. Microbiol. 18, 4244.

6. Danielsen, M. and Wind, A. (2003) Susceptibility of Lactobacillus spp. to antimicrobial agents. Int. J. Food Microbiol. 82, 1-11.

7. De Rodas, B. Z., Gilliland, S. E., and Maxwell, C. V. (1996) Hypocholesterolemic action of Lactobacillus acidophilus ATCC 43121 and calcium in swine with hypercholesterolemia induced by diet. J. Dairy Sci. 79, 2121-2128.

8. Guzik, T. J., Korbut, R., and Adamek-Guzik, T. (2003) Nitric oxide and superoxide in inflammation and immune regulation. J. Physiol. Pharmacol. 54, 469-487.

9. Ha, C. G., Cho, J. K., Chai, Y. G., and Heo, K. C. (2004) Isolation and identification of lactic bacteria containing superior activity of the bile salt deconjugation. Korean J. Food Sci. Ani. Resour. 24, 164-170.

10. Hoa, N. T., Baccigalupi, L., Huxham, A., Smertenko, A., Van, P. H., Ammendola, S., Ricca, E., and Cutting, A. S. (2000) Characterization of Bacillus species used for oral bacteriotherapy and bacterioprophylaxis of gastrointestinal disorders. Appl. Environ. Microbiol. 66, 5241-5247.

11. Holzapfel, W. H., Geisen, R., and Schillinger, U. (1993) Biological preservation of foods with reference to protective cul- 
tures, bacteriocins and food-grade enzymes. Int. J. Food Microbiol. 24, 343-362.

12. Ibrahim, S. A. and Bezkorovainy, A. (1993) Survival of bifidobacteria in the presence of bile salts. J. Sci. Food Agric. 65, 351-354.

13. Jun, K. D., Lee, K. H., Kim, W. S., and Paik, H. D. (2000) Microbiological identification of medical probiotic Bispan strain. Kor. J. Appl. Microbiol. Biotechnol. 28, 124-127.

14. Kanno, S., Shouji, A., Tomizawa, A., Hiura, T., Osanai, Y., Ujibe, M., Obara, Y., Nakahata, N., and Ishikawa, M. (2006) Inhibitory effect of naringin on lipopolysaccharide (LPS)induced endotoxin shock in mice and nitric oxide production in RAW 264.7 macrophages. Life Sci. 78, 673-681.

15. Karpuzoglu, E. and Ahmed, S. A. (2006) Estrogen regulation of nitric oxide and inducible nitric oxide synthase (iNOS) in immune cells: Implications for immunity, autoimmune diseases, and apoptosis. Nitric Oxide 15, 177-186.

16. Kim, S. J. (2005) Potential probiotic properties of lactic acid bacteria isolated from Kimchi. Food Sci. Biotechnol. 14, 547-550.

17. Kimura, K., McCartney, A. L., McConnel, M. A., and Tannock, G. W. (1997) Analysis of fecal population of bifidobacteria and lactobacilli and investigation of the immunological responses of their human hosts to predominant strains. Appl. Environ. Microbiol. 63, 3394-3398.

18. Klein, G. (2003) Taxonomy, ecology and antibiotic resistance of enterococci from food and the gastro-intestinal tract. Int. J. Food Microbiol. 88, 123-131.

19. Kobayashi, Y., Tohyama, K., and Terashima, T. (1974) Tolerance of the multiple antibiotic resistant strains, $L$. casei PSR 3002, to artificial digestive fluids. Jpn. J. Microbiol. 29, 691697.

20. Lee, S. B. and Choi, S. H. (2006) Isolation and identification of probiotic Lactobacillus isolates for calf meal supplements. Korean J. Food Sci. Ani. Resour. 26, 106-112.

21. Liao, J. K., Shin, W. S., Lee, W. Y., and Clark, S. L. (1995) Oxidized low-density lipoprotein decreases the expression of endothelial nitric oxide synthase. J. Biol. Chem. 270, 319324.

22. Lim, S. J., Jang, S. S., and Kang, D. K. (2007) Probiotic properties of Lactobacillus salivarius CPM-7 isolated from chicken feces. Kor. J. Microbiol. Biotechnol. 35, 98-103.

23. Mainville, I., Arcand, Y., and Farnworth, E. R. (2005) A dynamic model that simulates the human upper gastrointestinal tract for the study of probiotics. Int. J. Food Microbiol. 99, 287-296.

24. Marin, J. and Rodriguez-Martinez, M. A. (1997) Role of vascular nitric oxide in physiological and pathological conditions. Pharmacol. Ther. 75, 111-134.

25. McCartney-Francis, N., Allen, J. B., Mizel, D. E., Albina, J. E., Xie, Q. W., Nathan, C. F., and Wahl, S. M. (1993) Suppression of arthritis by an inhibitor of nitric oxide synthase. J. Exp. Med. 178, 749-754.

26. Muriuki, F. K., Ogara, W. O., Njeruh, F. M., and Mitema, E. S. (2001) Tetracycline residue levels in cattle meat from
Nairobi salughter house in Kenya. J. Vet. Sci. 2, 97-101.

27. Oleszak, E. L., Katsetos, C. D., Kuzmak, J., and Varadhachary, A. (1997) Inducible nitric oxide synthase in Theiler's murine encephalomyelitis virus infection. J. Virol. 71, 32283235.

28. Park, H. S., Lee, J. H., and Uhm, T. B. (1999) Probiotic properties of Lactobacillus salivarius isolated from piglet intestines. J. Korean Soc. Food Sci. Nutr. 28, 830-836.

29. Pascual, M., Hugas, M., Badiola, J. I., Monfort, J. M., and Garriga, M. (1999) Lactobacillus salivarius CTC2197 prevents Salmonella enteritidis colonization in chickens. Appl. Environ. Microbiol. 65, 4981-4986.

30. Pool-Zobel, B. L., Neudecker, C., Domizlaff, I., Ji, S., Schillinger, U., Rumney, C., Moretti, M., Vilarini, I., ScassellatiSforzolini, R., and Rowland, I. (1996) Lactobacillus- and Bifidobacterium-mediated antigenotoxicity in the colon of rats. Nutr. Cancer 26, 365-380.

31. Reddy, N. R., Roth, S. M., Eigel, W. N., and Pierson, M. D. (1998) Foods and food ingredients for prevention of diarrhoea diseases in children in developing countries. J. Food Prot. 51, 66-75.

32. Sanders, M. E. (2003) Probiotics: Considerations for human health. Nutr. Rev. 61, 91-99.

33. Shanahan, F. (2004) Probiotics in inflammatory bowel disease-therapeutic rationale and role. Adv. Drug Deliver Rev. 56, 809-818.

34. Shin, M. S., Kim, H. M., Kim, G. T., Huh, C. S., Bae, H. S., and Back, Y. J. (1999) Selection and characteristics of Lactobacillus acidophilus isolated from Korean feces. Kor. J. Food Sci. Technol. 31, 495-501.

35. Vinderola, C. G. and Reinheimer, J. A. (2003) Lactic acid starter and probiotic bacteria: a comparative "in vitro" study of probiotic characteristics and biological barrier resistance. Food Res. Int. 36, 895-904.

36. Vizoso Pinto, M. G., Franz, C. M. A. P., Schillinger, U., and Holzapfel, W. H. (2006) Lactobacillus spp. with in vitro probiotic properties from human faeces and traditional fermented products. Int. J. Food Microbiol. 109, 205-214.

37. Weisz, A., Cicatiello, L., and Esumi, H. (1996) Regulation of the mouse inducible-type nitric oxide synthase gene promoter by interferon-gamma, bacterial lipopolysaccharide and NG-monomethyl-L-arginine. Biochem. J. 316, 209-215.

38. Wierup, M. (2001) The experience of reducing antibiotics used in animal production in the Nordic countries. Int. $J$. Antimicrob. Ag. 18, 287-290.

39. Xanthopoulos, V., Litopoulou-Tzanetaki, E., and Tzanetakis, N. (2000) Characterization of Lactobacillus isolates from infant faeces as dietary adjuncts. Food Microbiol. 17, 205215.

40. Zhou, J. S., Pillidge, C. J., Gopal, P. K., and Gill, H. S. (2005) Antibiotic susceptibility profiles of new probiotic Lactobacillus and Bifidobacterium strains. Int. J. Food Microbiol. 98, 211-217.

$\overline{\text { (Received 2010.5.31/Revised 2010.7.22/Accepted 2010.7.22) }}$ 